\title{
Adhering to the 2017 Dutch Physical Activity Guidelines: A Trend over Time 2001-2018
}

\author{
Marjolein Duijvestijn *, Saskia W. van den Berg and G. C. Wanda Wendel-Vos \\ National Institute for Public Health and the Environment (RIVM), P.O. Box 1, 3720 BA Bilthoven, \\ The Netherlands; saskia.van.den.berg@rivm.nl (S.W.v.d.B.); wanda.vos@rivm.nl (G.C.W.W.-V.) \\ * Correspondence: marjolein.duijvestijn@rivm.nl; Tel.: +31-30-274-3969
}

Received: 10 December 2019; Accepted: 17 January 2020; Published: 21 January 2020

\begin{abstract}
Recently, new physical activity (PA) guidelines were adopted in the Netherlands consisting of two components: (1) addressing duration of moderate and vigorous PA, (2) bone and muscle strengthening activities. The aim of this study is to retrospectively assess the long-term trend in fulfilling the criteria of the new PA guidelines and to gain insight into which activities contribute to changes over time. Data were available for 2001-2018 of a nationally representative sample of approximately 7000 Dutch citizens aged 12 years and over using the Short Questionnaire to Assess Health-enhancing physical activity (SQUASH). Multiple logistic regression analysis was performed by age, sex, and level of education. Overall, a positive trend was found from 39.9\% adherence in 2001 to $46.0 \%$ in 2018. Adherence levels among adolescents decreased and increased among adults and seniors. Intermediate and higher educated groups showed positive trends over time whereas a stable trend was observed among lower educated. Activities contributing most to changes over time were sports, leisure time walking, and strenuous occupational activities. In the period 2001-2018, though an increasing trend was found, less than half of the population was sufficiently active. Special effort is necessary to reach adolescents, seniors, and lower educated groups in PA promotion programs.
\end{abstract}

Keywords: physical activity; guideline; exercise; health; trend; bone and muscle strengthening activities; cross-sectional

\section{Introduction}

Non-communicable diseases (NCD) are a major health problem that could be countered by the elimination of physical inactivity [1]. In 2016, 28\% of the world population was considered inactive, with a prevalence twice as high in Western countries [2]. It was estimated that $6 \%-10 \%$ of the burden of disease from NCD is attributable to physical inactivity [3]. In addition, the economic burden of physical inactivity on global health care costs has been conservatively estimated at 54 billion dollars in 2013 [4]. Insight into levels of physical activity and the trend over time, including preferences for certain types of activity among particular population groups is of crucial importance for policy makers [5].

In 2018, the World Health Organization (WHO) launched the global action plan on physical activity with the aim to help countries to scale up policy actions to promote physical activity [6]. The action plan provides a framework of effective and feasible policy actions at all levels. The goals set by the WHO for reducing physical inactivity are a relative reduction of $10 \%$ by 2025 and $15 \%$ by the year 2030 [6]. WHO has identified ten key areas for supporting countries in reaching these goals, one of which is to 'monitor progress and impact of physical activity' [6]. Currently in the Netherlands, three policies focus on sport and physical activity. First, the national sport agreement aims to preserve and strengthen the sport infrastructure, ensuring a safe environment for everyone to have fun and enjoy physical activity and sport [7]. Second, the cycling agenda comprehends increasing cycling 
kilometers with $20 \%$ (2017-2027) and to motivate an extra 200,000 employees to take up cycling to work [8]. Third, the Prevention Agreement states, among others, that adherence to the Dutch physical activity guidelines should increase to a level of $75 \%$ of the general population in 2040 as opposed to $47 \%$ in the year 2017 [9].

The current Dutch physical activity guidelines were adopted in 2017 as a result of an advisory report from the Dutch Health Council $[10,11]$. Table 1 shows the different elements of these guidelines.

Table 1. Dutch physical activity guidelines 2017 [10,11].

\begin{tabular}{|c|c|}
\hline Adults and Older People $\geq 18$ Years of Age & Children and Adolescents 4-18 Years of Age \\
\hline $\begin{array}{l}\text { Physical activity is good for you-the more, } \\
\text { the better } \\
\text { Engage in physical activity of moderate intensity } \\
\text { for at least } 150 \text { min every week, spread over } \\
\text { several different days. For example, walking and } \\
\text { cycling. The longer you are physically active, } \\
\text { and the more frequent and/or more vigorous the } \\
\text { activity, the more your health will benefit. } \\
\text { Do activities that strengthen your muscles and } \\
\text { bones at least twice a week. Older people } \\
\text { should combine these with balance exercises. } \\
\text { And: avoid spending long periods sitting down. }\end{array}$ & $\begin{array}{l}\text { Physical activity is good for you-the more, } \\
\text { the better } \\
\text { Engage in physical activity of moderate intensity } \\
\text { for at least one hour every day. The longer you } \\
\text { are physically active, and the more frequent } \\
\text { and/or more vigorous the activity, the more your } \\
\text { health will benefit. } \\
\text { Do activities that strengthen your muscles and } \\
\text { bones at least twice a week. Older people } \\
\text { should combine these with balance exercises. } \\
\text { And: avoid spending long periods sitting down. }\end{array}$ \\
\hline
\end{tabular}

This article will describe the second and third element: the time spent on physical activity of at least moderate intensity and the frequency of activities that strengthen muscles and bones. Both these components must be met to adhere to the physical activity guidelines. Compared to the former Dutch physical activity guidelines, the second component addressing bone and muscle strengthening activities is newly added [12]. To evaluate goals on adherence to the physical activity guidelines, monitoring and analysing trends over time are necessary [13-15].

Multiple studies have reported physical (in) activity levels at country [16-21], European [15,22], and/or global level $[2,14,23]$. A number of studies have also considered the development over time $[2,18-20,24]$. All studies included a national representative sample and reported separately on sex [2], age [18-20,24], and several on level of education as well [19,20,24]. However, these studies often only assessed a few time points over a period of less than 15 years $[18,19,24]$. A study by Guthold et al. (2018) was the first to assess a global long-term trend (2001-2016) of physical inactivity, distinguishing sex and income level [2]. They had to make many assumptions due to the use of several different questionnaires and only $55 \%$ of countries having data available for more than one time point [2]. In our study, annual data were available from 2001 to 2018. During this period, the same questionnaire was used. The large sample size of the dataset enables a selection for subgroups. Furthermore, the questionnaire items allow us to gain insight in the relative contribution of specific activities. To our knowledge, only few studies had this opportunity [25]. As far as we know, we are the first to combine yearly time points to assess long-term trends in adhering to a physical activity guideline and addressing activities that underlie changes over time.

In other countries, the bone and muscle strengthening component of a guideline rarely is measured in national surveillance systems and therefore most of the time not considered when calculating national prevalence estimates [26]. One study in Scotland has made an effort to provide detailed national representative information on the proportions meeting muscle strengthening guidelines [25]. They assessed the prevalence of muscle strengthening guidelines and participation in muscle strengthening guideline-specific exercises [25]. However, they did not integrate this measure with moderate to vigorous physical activity (MVPA). Another national study in Australia and the United States did examine incorporating muscle strengthening activities into their physical activity guideline. This resulted in lower adherence levels compared to the guideline of only 
MVPA [16,21]. To date, only limited knowledge is available concerning the attribution of bone and muscle strengthening exercises, to a guideline consisting of a combination of MVPA and bone and muscle strengthening exercises.

The overall aim of the present study is to gain more insight into adherence to the Dutch physical activity guidelines and its separate components addressing moderate and highly intense physical activity, and bone and muscle strengthening activities. Doing so by assessing the trend over time in the prevalence of adhering to the Dutch physical activity guidelines and underlying components. Additionally, to identify underlying physical activities that may be responsible for changes over time observed in adherence to the guidelines.

\section{Materials and Methods}

\subsection{Study Design and Participants}

From the year 2001, physical activity levels of the Dutch population were assessed on a yearly basis as part of a cross-sectional survey called the Dutch Health Survey/Lifestyle Monitor by Statistics Netherlands in collaboration with the National Institute for Public Health and the Environment [27-30]. In this survey, a two-stage stratified sampling design (1. municipalities and 2. individuals) was used to select participants from the Dutch Personal Records Database [31]. The sample was spread out over all months of the year [29]. Participants were requested to fill in the survey on paper or online, non-responders were approached face-to-face or by phone for an interview [27-29]. After weighting based on demographic characteristics such as age, sex, and marital status, the data are nationally representative of the Dutch population [32]. For comparability reasons, the present study used data from citizens aged 12 years and older, a sample of approximately 7000 Dutch citizens each year. Approval of the medical ethical committee was not necessary.

\subsection{Demographic Characteristics}

Participant characteristics (age, sex, level of education) were derived from the survey. Age groups were defined as adolescents (12 to 17 year old's), adults (18 to 64 year old's), and seniors (65 years and over). Highest attained level of education was classified as low (no, elementary, or low vocational/secondary schooling), intermediate (intermediate vocational or intermediate/higher secondary schooling), or high (higher vocational schooling or university) from the age of 25 . Although information on the attained education was available bellow the age of 25 , it was considered that most people would not have attained their highest level of education yet.

\subsection{Physical Activity}

Physical activity levels were assessed with the validated Short Questionnaire to Assess Health-enhancing physical activity (SQUASH) [33]. The SQUASH has been validated for adults $(r=0.43)$ [33], adolescents $(r=0.50)$ [34], older adults $(r=0.48)$ [35], and patient groups $(r=0.67)$ [36] by using double labelled water [34], accelerometer data [33,36], or another physical activity questionnaire [35]. The SQUASH domains and activities are presented in Table 2 [33]. Based on these items, using a standardized algorithm, adherence to the Dutch physical activity guidelines (Table 1 ) was calculated. In the algorithm, activities and sports were categorized as low $(<3.0 \mathrm{MET})$ or moderate to vigorous intensity ( $\geq 3.0 \mathrm{MET}$ ) based on metabolic equivalent (MET) scores [37]. Based on the available data and the definition of the physical activity guidelines by the Dutch Health Council, activities and sports were categorized as muscle and/or bone strengthening $[10,11]$. Bone strengthening activities were defined as activities involving strength training and bearing body weight, for example, jumping, walking stairs, walking, running, and dancing $[10,11]$. Muscle strengthening activities included activities to increase strength, capacity, endurance, and muscle size, for example, exercise with the use of bodyweight and aerobic activities. Aerobic activities should involve large muscle groups, for example, walking, swimming, cycling, and dancing [11]. The categorization was reviewed 
by an expert group. Appendix A gives an overview of the MET scores corresponding to the activities and the categorization for bone and muscle strengthening activities.

Table 2. Domains and activities of the Short Questionnaire to Assess Health-enhancing physical activity (SQUASH) [33].

\begin{tabular}{|c|c|c|c|}
\hline Domain & Activities $^{+}$ & Domain & Activities $^{+}$ \\
\hline Transport to work/school & $\begin{array}{l}\text { Walking to work/school } \\
\text { Cycling to work/school }^{\dagger}\end{array}$ & At work/school & $\begin{array}{l}\text { Working activities, light/moderate * } \\
\text { Working activities, strenuous * }\end{array}$ \\
\hline Leisure time & $\begin{array}{l}\text { Walking in leisure time }{ }^{+} \\
\text {Cycling in leisure time } \\
\text { Gardening }^{+} \\
\text {Odd jobs }^{+}\end{array}$ & $\begin{array}{l}\text { Household } \\
\text { Sports }\end{array}$ & $\begin{array}{c}\text { Household activities, light/moderate } \\
\text { Household activities, strenuous }^{\dagger} \\
\text { Sports (max. 4) }\end{array}$ \\
\hline
\end{tabular}

${ }^{\dagger}$ assessed in number of days per week and hour/minutes on those days. ${ }^{*}$ assessed in hours per week and for intensity: light/moderate activities at work were defined as sitting/standing work with occasional walking such as office work or walking during work with light loads, strenuous activities were defined as walking during work or work for which heavy loads must be lifted regularly.

\subsection{Data Analysis}

General population characteristics for each year were described (age, sex, level of education). Weighted prevalence were calculated for (i) meeting the full physical activity guidelines, (ii) meeting the MVPA component, (iii) meeting the bone and muscle strengthening component.

To analyze the trend over time, a logistic regression was performed with adhering to the overall guidelines or component as the dependent variable, resulting in three separate models. Time, the year of the measurement, was added to the model as a continuous independent variable. To investigate interaction by sex, age (in categories), and level of education (in categories) interaction terms were added one by one to the model. Data from 124,823 participants of 12 years and older were available for analysis of which 101,260 participants were from the age of 25 . When the terms were statistically significant, stratified analysis was performed for subgroups. Adjusted odds ratios (ORs) and their 95\% confidence intervals (CIs) were presented with three decimals, as ORs were interpreted per year, thereby expecting small ratios.

To get insight in the underlying activities that could explain observed trends, weighted mean time spent on activities (hours/week) was further investigated. The mean time spent on activities was assumed to represent duration and frequency and was presented for relevant subgroups (age, sex, level of education). Difference between years in time spent on activities of at least $0.5 \mathrm{~h}$ per week were considered to be relevant. Statistical analysis was conducted using IBM SPSS 22.0 statistical software (SPSS Inc. an IBM Company, Chicago, IL, USA). For all statistical tests, a $p$-value of $<0.01$ was used to indicate statistical significance.

\section{Results}

Table 3 shows the population size, general characteristics for all years, and the prevalence rates for 2018. The Dutch population distribution changed between 2001 and 2018, this is represented in our study population. For example, the proportion of seniors increased over the years and the proportion of lower educated declined. 
Table 3. Population size $(n)$ for each year included in the analysis stratified by age, sex, and by level of education (\#\%) and the prevalence of adherence to the Dutch physical activity guidelines and components: (1) moderate and vigorous intense physical activity, (2) bone and muscle strengthening activities, for all subgroups (\#,\#\%).

\begin{tabular}{|c|c|c|c|c|c|c|c|c|c|c|}
\hline \multirow[b]{2}{*}{ Year } & \multicolumn{2}{|c|}{ Total $(n)$} & \multicolumn{3}{|c|}{ Age Group (\%) * } & \multicolumn{2}{|c|}{$\operatorname{Sex}(\%) *$} & \multicolumn{3}{|c|}{ Level of Education $(\%)^{\dagger, \delta}$} \\
\hline & $\geq 12$ Years & $\geq 25$ Years & $\begin{array}{l}\text { Adolescents } \\
\text { (12-17) }\end{array}$ & $\begin{array}{l}\text { Adults } \\
(18-64)\end{array}$ & $\begin{array}{c}\text { Seniors } \\
(65+)\end{array}$ & Male & Female & Lower & Intermediate & Higher \\
\hline 2001 & 5971 & 4915 & 9 & 75 & 16 & 48 & 52 & 43 & 34 & 23 \\
\hline 2002 & 5834 & 4775 & 9 & 74 & 17 & 47 & 53 & 42 & 34 & 24 \\
\hline 2003 & 6566 & 5409 & 10 & 74 & 16 & 48 & 52 & 41 & 34 & 25 \\
\hline 2004 & 7584 & 6157 & 10 & 74 & 16 & 48 & 52 & 31 & 39 & 30 \\
\hline 2005 & 7128 & 5930 & 9 & 73 & 18 & 48 & 52 & 42 & 34 & 24 \\
\hline 2006 & 6733 & 5601 & 9 & 73 & 18 & 48 & 52 & 41 & 34 & 25 \\
\hline 2007 & 5951 & 4953 & 9 & 72 & 19 & 47 & 53 & 41 & 33 & 26 \\
\hline 2008 & 6212 & 5170 & 9 & 72 & 20 & 48 & 52 & 39 & 34 & 27 \\
\hline 2009 & 5962 & 3248 & 8 & 71 & 21 & 48 & 52 & 37 & 34 & 29 \\
\hline 2010 & 7218 & 6085 & 7 & 72 & 21 & 47 & 53 & 38 & 30 & 32 \\
\hline 2011 & 6262 & 5238 & 7 & 71 & 22 & 48 & 52 & 39 & 29 & 32 \\
\hline 2012 & 6349 & 6085 & 7 & 71 & 22 & 47 & 53 & 34 & 33 & 34 \\
\hline 2013 & 6444 & 5241 & 7 & 70 & 23 & 46 & 54 & 26 & 41 & 33 \\
\hline 2014 & 7859 & 6331 & 9 & 69 & 23 & 51 & 49 & 30 & 40 & 30 \\
\hline 2015 & 7783 & 6272 & 9 & 69 & 22 & 52 & 48 & 30 & 40 & 30 \\
\hline 2016 & 7646 & 6137 & 9 & 68 & 23 & 48 & 52 & 30 & 38 & 31 \\
\hline 2017 & 8819 & 6598 & 9 & 66 & 25 & 49 & 51 & 28 & 40 & 32 \\
\hline 2018 & 8502 & 7115 & 8 & 70 & 22 & 49 & 51 & 26 & 39 & 35 \\
\hline \multicolumn{11}{|c|}{ Prevalence rates for adherence to the physical activity guidelines in $2018(\#, \# \%)$} \\
\hline Overall & 46.0 & 46.2 & 33.9 & 50.1 & 37.0 & 48.1 & 43.9 & 34.3 & 45.5 & 56.5 \\
\hline Component 1 & 52.4 & 52.8 & 37.1 & 56.9 & 43.1 & 55.7 & 49.1 & 42.5 & 52.8 & 61.3 \\
\hline Component 2 & 78.2 & 77.6 & 84.2 & 79.1 & 72.9 & 78.2 & 78.3 & 67.4 & 77.3 & 86.3 \\
\hline
\end{tabular}

${ }^{*}$ Based on population size of $\geq 12$ years old ${ }^{\dagger}$ Based on population size of $\geq 25$ years old and categorized by highest attained level of education ${ }^{\delta}$ low (no, elementary, or low vocational/secondary schooling), intermediate (intermediate vocational or intermediate/higher secondary schooling), or high (higher vocational schooling or university). 
In $2018,46.0 \%$ of the total population aged 12 years and over adhered to the physical activity guidelines, $48.1 \%$ males and $43.9 \%$ females (Table 3). Adults adhered the most $(50.1 \%)$, followed by seniors (37.0\%) and adolescents (33.9\%). For level of education, the adherence levels increased with a higher level of education (low (34.3\%), intermediate (45.5\%), and high $(56.5 \%)$ ).

In general, adherence levels for component 2 , bone and muscle strengthening activities $(78.2 \%$ in 2018), are higher compared to component 1 , time spent on moderate to vigorous activities $(52.4 \%$ in 2018, Table 3). In that sense, component 1 determines the level of adherence to the physical activity guidelines for the larger part. However, still a proportion of the individuals does adhere to component 1 and not to component 2 as adherence to the overall guidelines $(46.0 \%$ in 2018$)$ is lower compared to component 1 (52.4\% in 2018).

Between 2001 and 2018, adherence to the Dutch physical activity guidelines increased from 39.9\% to $46.0 \%$, showing a stable to slightly increasing pattern (Figure 1a). This trend was similar for men and women $(p>0.01)$. For both adherence to the overall physical activity guidelines and the separate components, an interaction with age group was observed $(p<0.01)$. All prevalence data $(2001-2018)$ can be found in Appendix B.

a) Adherence to the Dutch physical activity guidelines by age group

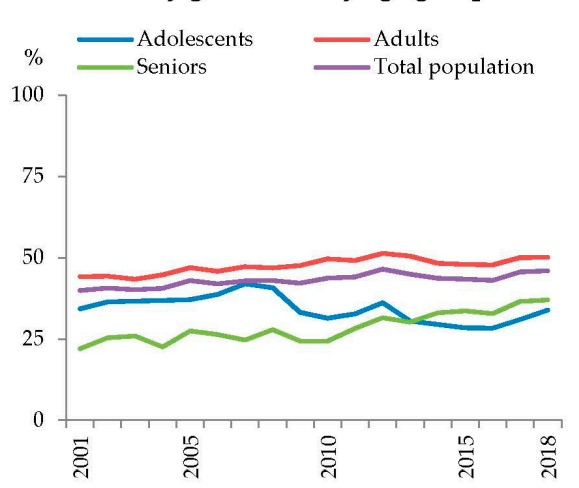

c) Adherence to component 2 by age group

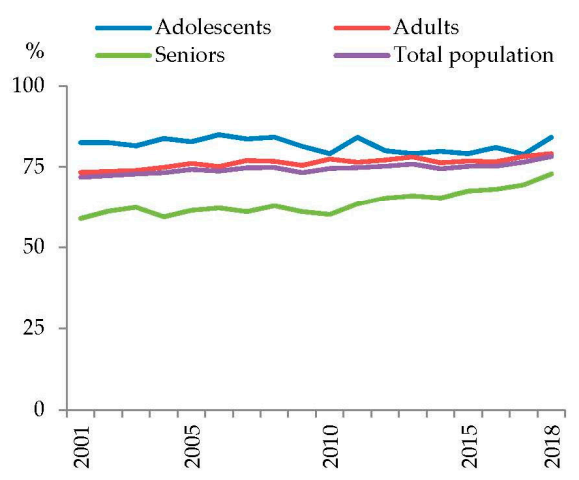

b) Adherence to component 1 by age group

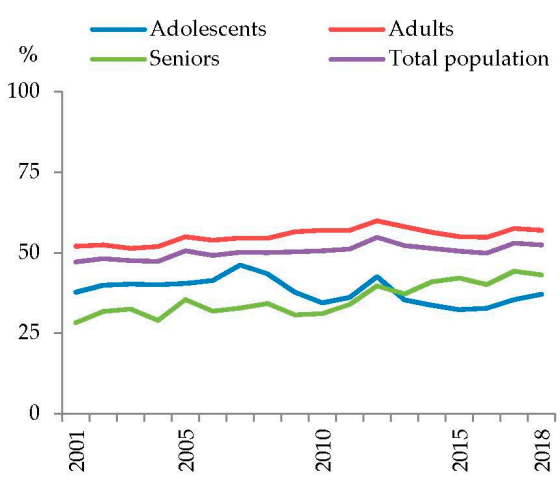

d) Adherence to the Dutch physical activity guidelines by level of education

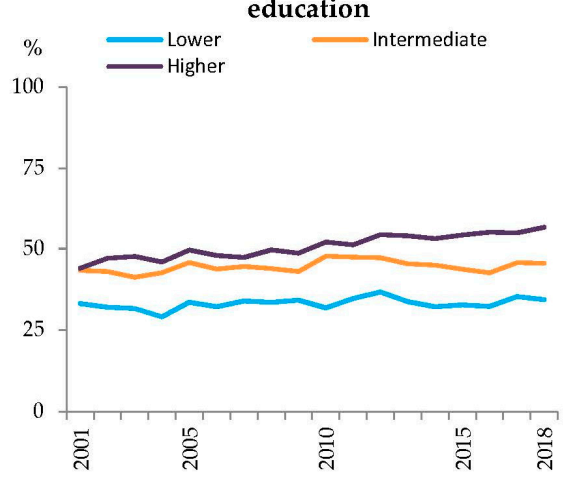

Figure 1. Adherence levels to the Dutch physical activity guidelines (\%) consisting of component 1; 150 moderate-and vigorous intense physical activity per week for adults, one hour per day for adolescents and component 2; two times per week bone and muscle strengthening activities for adults, three times for adolescents, stratified by age groups (12-17, 18-64, 65+) and level of education. (a) Adherence to guidelines for age groups, (b) adherence to component 1 for age groups, (c) adherence to component 2 for age groups, (d) adherence to the guidelines by level of education.

Among adolescents, a small negative trend over time was found with an odds for adherence to the overall guidelines of 0.979 [95\% confidence interval (CI) 0.972:0.986] per year between 2001 and $2018(34.3 \%$ and $33.9 \%)$. A similar trend was seen for component $1(p<0.01)$, whereas no trend was 
found for component 2 ( $p=0.27$, Figure 1). The decreasing trend may be explained by changes in time spent on specific activities (Figure 2a). Time spent on sports showed the largest difference between 2001 (i.e., 5.7 h/week) and 2018 (i.e., 4.6 h/week). Also, time spent on cycling to school/work clearly decreased during this period (4.2 vs. $3.6 \mathrm{~h} /$ week). On the other hand, an increase was seen in time spent on walking to work/school (0.7 vs. $1.3 \mathrm{~h} /$ week) and during leisure time (1.0 vs. $2.1 \mathrm{~h} /$ week).

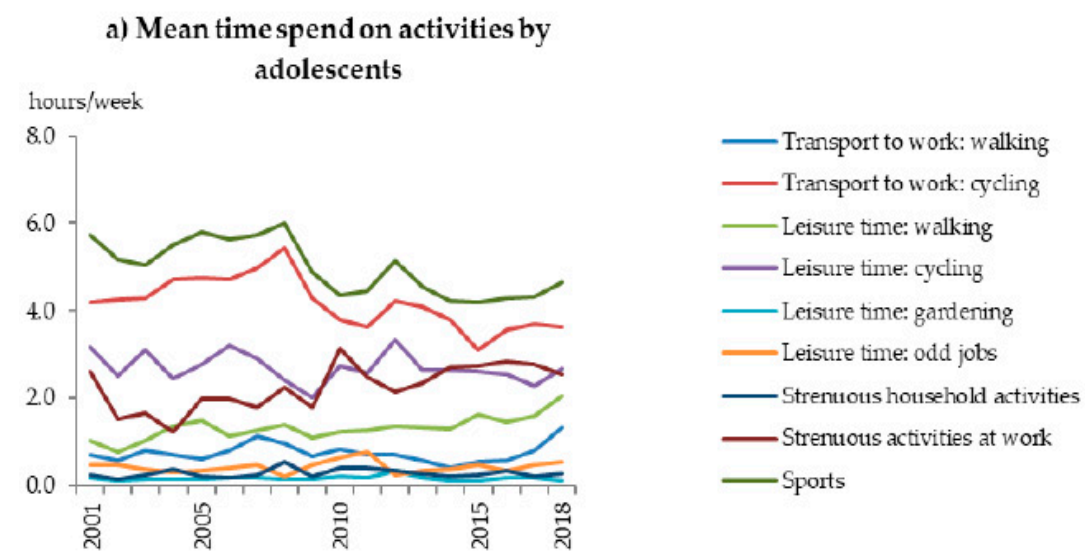

b) Mean time spend on activities by adults

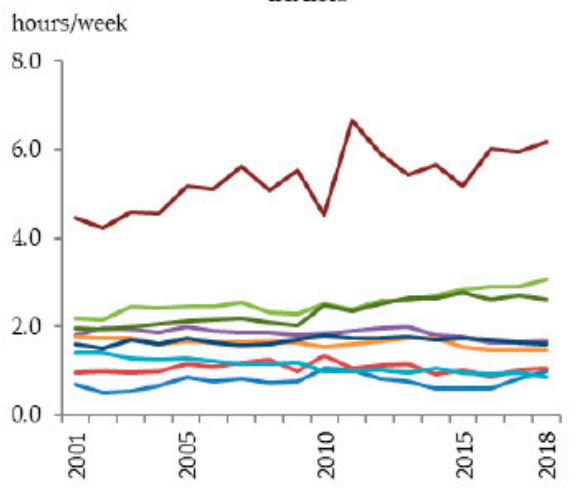

c) Mean time spend on activities by

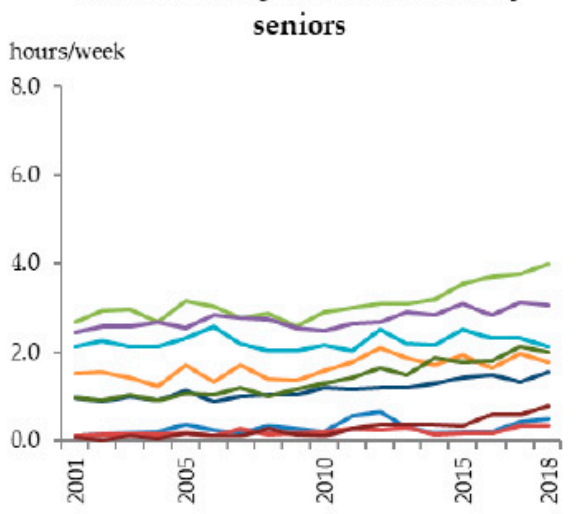

Figure 2. Mean time spend on activities at work or school, in household, during leisure time and sports per week for each year (2001-2018) stratified for age groups, (a) adolescents (12-17 years old), (b) adults (18-64 years old), (c) seniors (65+ years old).

For adults, a small positive trend over time was observed (OR 1.017 per year [95\% CI 1.014:1.019]) in adherence to the overall guidelines between 2001 and 2018 (44.2\% and 50.1\%, Figure 1a). Similar trends were seen for component 1 ( $p<0.01$, Figure $1 b)$ and component $2(p<0.01$, Figure $1 c)$. Subsequently, adults reported more time spent on several activities between 2001 and 2018 (Figure 2b). More time was spent on strenuous activity at work ( $4.5 \mathrm{vs} .6 .2 \mathrm{~h} /$ week), sports (1.9 vs. $2.6 \mathrm{~h} /$ week), and leisure time walking ( 2.2 vs. 3.1 h/week, Figure $2 \mathrm{~b}$ ). Gardening is the only activity for which less time was spent in 2018 compared to 2001 (1.4 vs. $0.9 \mathrm{~h} /$ week).

Among seniors, a positive trend in adherence to the overall guidelines (OR 1.047 per year [95\% CI 1.041:1.052]) was found as well, which was more pronounced than among adults (Figure 1a). Adherence to the physical activity guidelines among seniors increased from $22.0 \%$ in 2001 to $37.0 \%$ in 2018. The two underlying components showed the same increasing pattern during this period $(p<0.01$, Figure $1 \mathrm{~b}, \mathrm{c})$. The increasing trend may be explained by increasing amounts of time spent on walking as a leisure activity ( 2.7 vs. $4.0 \mathrm{~h} /$ week), sports (1.0 vs. $2.0 \mathrm{~h} /$ week), and strenuous household activities (1.0 vs. 1.6 h/week, Figure 2c) between 2001 and 2018.

Besides an interaction with age, also an interaction with level of education was observed $(p<0.01)$. A small positive significant trend over time in adherence to the physical activity guidelines was found 
for intermediate (OR 1.006 per year [95\% CI 1.003:1.010]) and higher educated (OR 1.028 per year [95\% CI 1.024:1.033]). Whereas, a stable trend over time was observed for lower educated $(p=0.97,2001$ : $33.1 \%, 2018: 34.3 \%$ ). Adherence to the overall guidelines increased for intermediate educated from $43.3 \%$ to $45.5 \%$ and for higher educated from $44.0 \%$ to $56.5 \%$ (Figure $1 \mathrm{~d}$ ). Similar trends were seen for component 1 and 2 ( $p<0.01)$. Over the years (2001 vs. 2018), intermediate educated showed an increase in time spent on strenuous activities at work ( 4.9 vs. $6.2 \mathrm{~h} /$ week) and leisure time walking (2.4 vs. 3.4 h/week, Figure 3b). While, they spent less time on gardening (1.9 vs. 1.3 h/week). Higher educated showed an increase in time spent on sports ( $2.0 \mathrm{vs} .3 .2 \mathrm{~h} /$ week), strenuous activities at work (1.0 vs. $2.8 \mathrm{~h} /$ week), and leisure time walking (2.1 vs. $3.1 \mathrm{~h} /$ week, Figure $3 \mathrm{c}$ ).

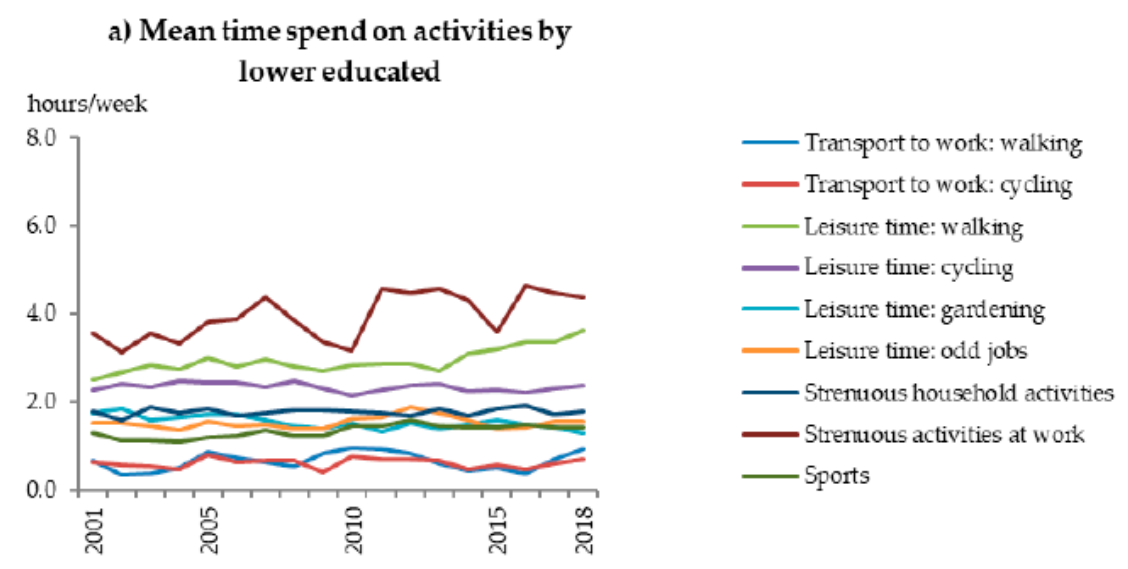

b) Mean time spend on activities by intermediate educated
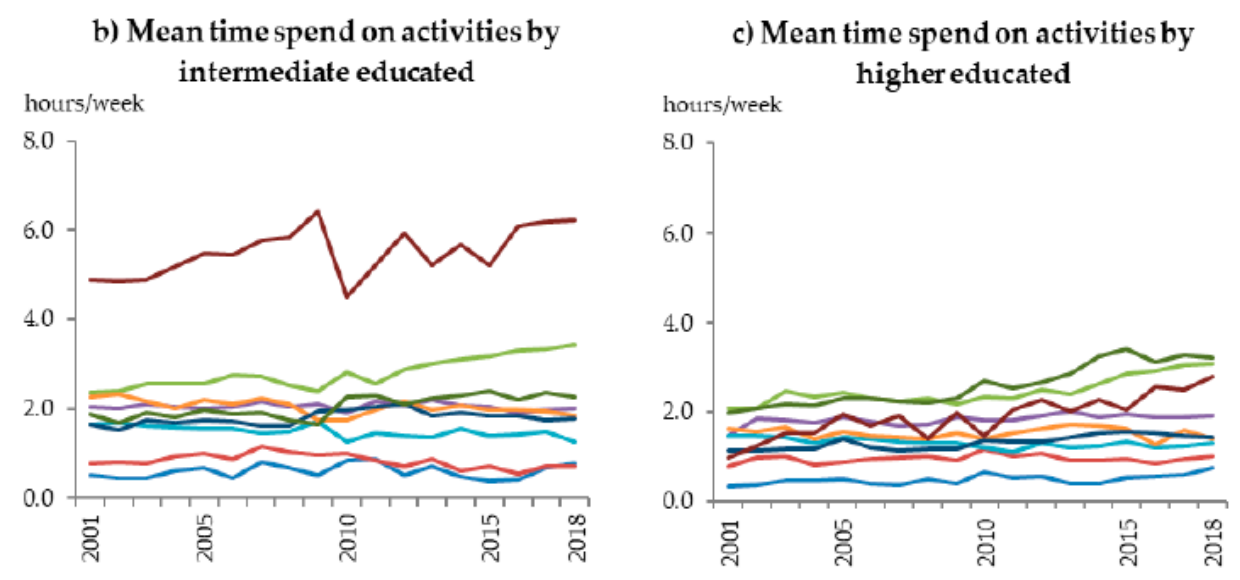

Figure 3. Mean time spend on activities at work or school, in household, during leisure time and sports per week for each year stratified for level of education, (a) lower educated (no, elementary, or low vocational/secondary schooling), (b) intermediate educated (intermediate vocational or intermediate/higher secondary schooling), (c) higher educated (higher vocational schooling or university).

\section{Discussion}

In the present study, we found that from 2001 to 2018, adherence to the Dutch physical activity guidelines increased for adults, seniors, and the intermediate and higher educated. An inverse trend was found for adolescents and a stable trend was found for the lower educated. Similar trends were seen for the two underlying components. Generally, adults adhered the most to the physical activity guidelines and seniors the least. Although, seniors showed the largest improvement over time. The underlying physical activity pattern for the trend over time of the components differed for each age and level of education group. In general, the activities that contributed most to changes in adhering to the Dutch physical activity guidelines were strenuous activities at work, sports, and walking during leisure time. 
In 2018, less than half of the Dutch population over 12 years old adheres to the physical activity guidelines $(46.0 \%)$. Several other countries have reported adherence levels on their physical activity guidelines; $65.2 \%$ of American adults [19], 45\% of Australian adults [38], and 66\% of English males and $58 \%$ of English female aged 16 year and older [39]. However, for methodological reasons, comparisons of adherence rates between countries must be treated with caution. First of all, these countries use different definitions of being sufficient physical active compared to the Netherlands and each other. Moreover, various validated and unvalidated questionnaires exist and are used by countries to assess physical activity levels, prohibiting clear comparison between countries [40]. Therefore, differences in methodology should be taken into account when comparing results between studies and countries. Nonetheless, it is of interest to examine relative differences between groups (e.g., sex, age), the trend over time, and share these outcomes between countries.

The Dutch physical activity guidelines consist of a moderate to vigorous physical activity (MVPA) and a bone and muscle strengthening component. A few studies assessed muscle strengthening activity in a physical activity guideline [16,21]. A recent national American study by Bennie et al. (2019) found that by adding muscle strengthening activities to an MVPA guideline, resulted in lower adherence levels (30.5\% vs. $20.3 \%$ ) [21]. The results are in line with our findings, though in our study, a smaller decline was found by the addition of a bone and muscle strengthening component, from $52.4 \%$ to 46.0\%. Bennie et al. (2019) used a different question to assess muscle strengthening activities. In this question, they explicitly excluded walking, running, and cycling. While in our study, these activities are seen as muscle strengthening based on a report by the Committee for Guidelines on Physical Activity [11]. Consequently, methodological differences can explain the different findings.

Strengths include the use of a large representative study population, giving us the possibility to investigate several subgroups. Data were available for each year from 2001 to 2018, with no missing data. Furthermore, the adherence to the physical activity guidelines was assessed retrospectively with the calculation method being the same for all years. Moreover, our findings give insight into which activities the population performs to adhere to the Dutch physical activity guidelines.

Despite the questionnaire being the same over time, data collection was subjected to methodological changes, which counts as a limitation of our study. Until 2013, data were collected by interviews and on paper. From 2014 and on, it was also possible to fill in the survey online. A report by Statistics Netherlands showed differences for a selection of variables due to this change [41]. The effect of this change has not been tested specifically for physical activity variables. In our results, no sudden changes were observed over all adherence levels to the physical activity guideline in 2014. Next to that, in essence, the questionnaire has been the same for all years, only a few years had small technical differences. For a few questions, technical differences involved the possibility to skip a question when not applicable to the participants situation. Despite small changes in the sample and collection method, it can be concluded that changes in methodology had a negligible effect on the results of our study.

Another limitation of our study includes the reliance on self-reported physical activity (e.g., overestimation, social desirable answers, recall bias). Specific limitation of the SQUASH questionnaire is an overestimation of physical activity due to the large number of items compared to other questionnaires. However, since 2001, the physical activity questionnaire has been the same in our study. Therefore, the bias related to overestimation may be considered a constant factor over time and less of a factor to consider when studying trends in physical activity levels. Therefore, it seems less likely that overestimation of physical activity levels has affected our trend conclusions. To overcome bias related to self-report, objective measurements could be used [42]. Using accelerometers in national surveillance systems has potential, however, more research on data quality and practical implications is necessary. For example, some activities may be poorly represented in accelerometer data. When assessing adherence to physical activity guidelines there might be a problem with including bone and muscle strengthening activities. Also, in countries where cycling is an important activity, such as the Netherlands, the total amount of physical activity may contain a systematic error. We also have to consider the fact that current physical activity guidelines and recommendations are largely based 
on self-reported studies using questionnaires when examining associations between activity and health-related outcomes [43]. Recommendations may change based on future large-scale longitudinal studies using objective measurements related to health-related outcomes [43]. Consequently, using objective measures in national surveillance systems aiming to assess physical activity levels related to good/better health may entail using a different indicator for health enhancing physical activity.

In our study, strenuous activities at work were found to attribute to an increasing adherence to the physical activity guidelines over time. However, it should be noted that previous research has indicated that occupational physical activity elevates cardiovascular risk [44]. In our article, strenuous activities at work were seen as activities to adhere to the physical activity guidelines, as the guidelines do not make a distinction where activities have taken place $[10,11]$. However, bias caused by including occupational activities in the analysis might be less pronounced as our population is national representative with only a portion in strenuous labor force. Nonetheless, occupational physical activities should not be seen as activities to be promoted for health-enhancing purposes [44].

In our study, adherence levels to the Dutch physical activity guidelines were found to differ between population groups. In general, physical activity levels tend to differ between men and women $[2,18,45]$. In the Netherlands, adherence levels are comparable between men and women. Another interesting finding of our study is that, seniors became more active. At the same time, physical activity levels are still relatively low compared to other age groups. Since, staying physically active is of tremendous importance to live independently as long as possible [46]. It is important to find ways to even further increase physical activity levels among seniors in the future. Opposite to seniors, adolescents became less active in the period 2001-2018. This is of concern because literature suggested that physical activity levels in childhood can track to adulthood [47,48]. This makes it of even more importance to facilitate physical activity among adolescent groups.

Next to developments within and between age groups, our results show an increasing gap of physical activity levels between lower educated at the one side and higher educated the other. The widening of the gap between higher and lower educated is well known for health status [49-52]. Also, we are not the first to confirm this for physical activity [50,51]. This emphasizes the need for physical activity promotion tailored to lower educational levels in order tackle these social economic differences in physical activity level.

It is likely that more population groups stay behind with respect to adherence to physical activity guidelines such as people with disabilities, overweight, or living in urban or rural areas. Future studies can contribute by providing more insight in such groups. It would also be interesting to answer questions on additional time needed to change non-adherence to adherence. In that respect, it may be helpful to take a closer look at specific activities that largely contribute to adherence such as specific sports or walking for particular purposes. It is advised to perform analysis separately for the two components, as some individuals already adhere to one component and not yet to the other. The outcome of such future studies on other relevant subgroups and specific activities could help tailoring physical activity promotion to certain target populations.

Overall, a small positive trend is observed from 2001 to 2018 for the Dutch population of 12 years and older. Still, adolescents, seniors, and lower educated groups are in need of focused attention to improve their adherence rates. Physical activity levels could be improved by policy changes aiming at tailoring physical activity promotion programs to subgroups [6]. To take a step in shaping these physical activity promotion programs, future studies could investigate which specific activities should be stimulated by policy actions to increase the physical activity levels.

From 2001 to 2018, adherence rates by the Dutch population increased from 39.9\% to $46.0 \%$. The Dutch government has the ambitious goal to have $75 \%$ of the population adhere to the physical activity guidelines by 2040 [9]. The goal set by the WHO might by more realistic with a relative increase of $15 \%$ in 2030 compared to 2018 [6]. Meaning, for the Dutch situation to reach 53\% adherence in 2030. Still, large measures and policy actions are necessary to accomplish either goals. Collaborations 
between sectors (e.g., health care, education, communities, and sport clubs) is of importance to increase population adherence rates and to target the groups with the lowest adherence levels [6].

\section{Conclusions}

Adherence levels for the Dutch physical activity guidelines have slightly increased between 2001 and 2018. Activities that contributed to changes in adhering to the Dutch physical activity guidelines were strenuous activities at work, sports, and walking during leisure time. Still, less than half of the population is sufficiently active. Especially adolescents, seniors, and groups with a lower level of education are in need of attention for tailored physical activity programs. In collaboration with multiple stakeholders actions can be taken to accomplish the adherence goals set out by the Dutch government and the WHO.

Author Contributions: S.W.v.d.B. and G.C.W.W.-V. conceived of and designed the study. M.D. did all the data cleaning and analysis, and wrote the first draft of the main paper. All the authors discussed the results and were involved in the critical revisions of the manuscript. All authors have read and agreed to the published version of the manuscript.

Funding: This study was funded by the Dutch ministry of health, welfare and sports. The funder was not involved in any part of the study.

Acknowledgments: We are grateful to Statistics Netherlands for making the data from the Health Survey (Statistics Netherlands) 2001-2013 and the Health Survey/Lifestyle Monitor (Statistics Netherlands in collaboration with the National Institute for Public Health and the Environment) 2014-2018 available.

Conflicts of Interest: The authors declare that they have no actual or potential competing financial interests.

\section{Appendix A}

Table A1. Metabolic equivalent (MET) scores of the activities and categorization in muscle and/or bone strengthening activities $[10,11,37]$.

\begin{tabular}{|c|c|c|c|c|}
\hline Domain & Activity & MET-Score & $\begin{array}{c}\text { Muscle } \\
\text { Strengthening * }\end{array}$ & $\begin{array}{c}\text { Bone } \\
\text { Strengthening * }\end{array}$ \\
\hline \multirow{2}{*}{$\begin{array}{c}\text { Transport to work } \\
\text { or school }\end{array}$} & Walking to work or school & 3.3 & YES & YES \\
\hline & Cycling to work or school & 5.8 & YES & $\mathrm{NO}$ \\
\hline \multirow{4}{*}{ Leisure time } & Walking during leisure time & 2.7 & YES & YES \\
\hline & Cycling during leisure time & 5.8 & YES & $\mathrm{NO}$ \\
\hline & Gardening & 3.8 & NO & NO \\
\hline & Odd jobs & 3.0 & $\mathrm{NO}$ & NO \\
\hline \multirow{2}{*}{ At work } & Working activities, light/moderate & 1.5 & $\mathrm{NO}$ & $\mathrm{NO}$ \\
\hline & Working activities, vigorous & 4.5 & NO & NO \\
\hline \multirow{2}{*}{ Household } & Household activities, light & 2.5 & $\mathrm{NO}$ & $\mathrm{NO}$ \\
\hline & Household activities, vigorous & 4.3 & $\mathrm{NO}$ & $\mathrm{NO}$ \\
\hline Sports & Sports & $\begin{array}{l}\text { Depends } \\
\text { on kind of } \\
\text { sport }\end{array}$ & $\begin{array}{c}\text { Depends on kind } \\
\text { of sport }\end{array}$ & $\begin{array}{c}\text { Depends on kind } \\
\text { of sport }\end{array}$ \\
\hline
\end{tabular}

* Based on the available data and the definition of the physical activity guidelines by the Dutch Health Council activities and sports were categorized as either muscle and/or bone strengthening. Bone strengthening activities were defined as activities involving strength training and bearing body weight, for example jumping, walking stairs, walking, running, and dancing. Muscle strengthening activities included activities to increase strength, capacity, endurance, and muscle size, for example, exercise with the use of bodyweight and aerobic activities. Aerobic activities should involve large muscle groups, for example, walking, swimming, cycling, and dancing. 


\section{Appendix B}

Table A2. Adherence levels to the Dutch physical activity guidelines in percentages, stratified by age groups, sex, and level of education.

\begin{tabular}{|c|c|c|c|c|c|c|c|c|c|c|}
\hline \multirow[b]{2}{*}{ Year } & \multicolumn{2}{|c|}{ Total (\%) } & \multicolumn{3}{|c|}{ Age Group (\%) * } & \multicolumn{2}{|c|}{$\operatorname{Sex}(\%) *$} & \multicolumn{3}{|c|}{ Level of Education $(\%)^{t, \delta}$} \\
\hline & $\begin{array}{l}\geq 12 \\
\text { Years }\end{array}$ & $\begin{array}{l}\geq 25 \\
\text { Years }\end{array}$ & $\begin{array}{c}\text { Adolescents } \\
(12-17)\end{array}$ & $\begin{array}{l}\text { Adults } \\
(18-64)\end{array}$ & $\begin{array}{c}\text { Seniors } \\
(65+)\end{array}$ & Male & Female & Lower & Intermediate & Higher \\
\hline 2001 & 39.9 & 39.3 & 34.3 & 44.2 & 22.0 & 39.9 & 39.9 & 33.1 & 43.3 & 44.0 \\
\hline 2002 & 40.6 & 39.6 & 36.4 & 44.3 & 25.3 & 40.1 & 41.2 & 32.0 & 43.0 & 47.1 \\
\hline 2003 & 40.1 & 39.0 & 36.6 & 43.3 & 25.9 & 41.4 & 38.9 & 31.6 & 41.2 & 47.6 \\
\hline 2004 & 40.6 & 39.6 & 36.8 & 44.7 & 22.6 & 40.5 & 40.6 & 29.1 & 42.6 & 45.9 \\
\hline 2005 & 43.0 & 41.7 & 37.1 & 46.9 & 27.5 & 41.9 & 43.9 & 33.6 & 45.8 & 49.6 \\
\hline 2006 & 41.9 & 40.2 & 38.7 & 45.8 & 26.4 & 42.3 & 41.6 & 32.2 & 43.7 & 47.9 \\
\hline 2007 & 42.9 & 41.1 & 42.0 & 47.2 & 24.7 & 41.6 & 44.0 & 33.9 & 44.5 & 47.3 \\
\hline 2008 & 43.0 & 41.6 & 40.7 & 46.8 & 27.9 & 42.2 & 43.7 & 33.5 & 43.9 & 49.6 \\
\hline 2009 & 42.1 & 41.6 & 33.2 & 47.5 & 24.3 & 42.8 & 41.5 & 34.2 & 43.0 & 48.6 \\
\hline 2010 & 43.7 & 42.6 & 31.4 & 49.6 & 24.4 & 44.1 & 43.4 & 31.8 & 47.7 & 52.0 \\
\hline 2011 & 44.1 & 43.4 & 32.7 & 49.1 & 28.3 & 44.0 & 44.1 & 34.7 & 47.4 & 51.1 \\
\hline 2012 & 46.4 & 45.8 & 36.1 & 51.3 & 31.5 & 47.8 & 45.1 & 36.7 & 47.2 & 54.3 \\
\hline 2013 & 44.9 & 44.7 & 30.5 & 50.5 & 30.2 & 45.9 & 44.0 & 33.7 & 45.4 & 53.9 \\
\hline 2014 & 43.6 & 43.6 & 29.4 & 48.2 & 33.0 & 43.8 & 43.5 & 32.2 & 44.9 & 53.1 \\
\hline 2015 & 43.4 & 43.5 & 28.4 & 47.9 & 33.6 & 43.9 & 42.9 & 32.7 & 43.7 & 54.2 \\
\hline 2016 & 43.0 & 43.3 & 28.3 & 47.8 & 32.8 & 43.4 & 42.6 & 32.3 & 42.6 & 55.0 \\
\hline 2017 & 45.6 & 45.8 & 31.0 & 50.0 & 36.6 & 47.1 & 44.2 & 35.3 & 45.7 & 54.8 \\
\hline 2018 & 46.0 & 46.2 & 33.9 & 50.1 & 37.0 & 48.1 & 43.9 & 34.3 & 45.5 & 56.5 \\
\hline
\end{tabular}

${ }^{*}$ Based on population size of $\geq 12$ years old. ${ }^{\dagger}$ Based on population size of $\geq 25$ years old and categorized by highest attained level of education. ${ }^{\delta}$ low (no, elementary, or low vocational/secondary schooling), intermediate (intermediate vocational or intermediate/higher secondary schooling), or high (higher vocational schooling or university).

Table A3. Adherence levels to the first component of the Dutch physical activity guidelines consisting of 150 moderate and vigorous intense physical activity per week for adults, one hour per day for adolescents, in percentages, stratified by age groups, sex, and level of education.

\begin{tabular}{|c|c|c|c|c|c|c|c|c|c|c|}
\hline \multirow[b]{2}{*}{ Year } & \multicolumn{2}{|c|}{ Total (\%) } & \multicolumn{3}{|c|}{ Age Group (\%) * } & \multicolumn{2}{|c|}{$\operatorname{Sex}(\%) *$} & \multicolumn{3}{|c|}{ Level of Education $(\%)^{t, \delta}$} \\
\hline & $\begin{array}{c}\geq 12 \\
\text { Years }\end{array}$ & $\begin{array}{c}\geq 25 \\
\text { Years }\end{array}$ & $\begin{array}{c}\text { Adolescents } \\
(12-17)\end{array}$ & $\begin{array}{l}\text { Adults } \\
(18-64)\end{array}$ & $\begin{array}{c}\text { Seniors } \\
(65+)\end{array}$ & Male & Female & Lower & Intermediate & Higher \\
\hline 2001 & 47.1 & 46.9 & 37.7 & 52.0 & 28.2 & 48.0 & 46.3 & 41.7 & 52.2 & 48.3 \\
\hline 2002 & 48.1 & 47.5 & 39.9 & 52.4 & 31.7 & 48.8 & 47.4 & 41.2 & 51.9 & 51.6 \\
\hline 2003 & 47.5 & 46.9 & 40.3 & 51.3 & 32.5 & 49.4 & 45.7 & 40.6 & 50.1 & 52.6 \\
\hline 2004 & 47.3 & 46.8 & 40.0 & 51.9 & 29.0 & 48.4 & 46.3 & 37.2 & 50.7 & 51.2 \\
\hline 2005 & 50.6 & 49.7 & 40.4 & 54.9 & 35.4 & 51.0 & 50.1 & 41.7 & 55.7 & 54.7 \\
\hline 2006 & 49.1 & 48.0 & 41.4 & 53.9 & 31.9 & 50.5 & 47.8 & 40.2 & 52.9 & 53.4 \\
\hline 2007 & 50.1 & 48.6 & 46.1 & 54.6 & 32.8 & 50.0 & 50.2 & 42.0 & 52.5 & 53.4 \\
\hline 2008 & 50.0 & 48.9 & 43.4 & 54.5 & 34.2 & 50.7 & 49.3 & 41.4 & 52.5 & 54.6 \\
\hline 2009 & 50.2 & 49.9 & 37.7 & 56.5 & 30.7 & 52.7 & 48.0 & 40.9 & 54.5 & 55.3 \\
\hline 2010 & 50.6 & 49.5 & 34.4 & 56.9 & 31.1 & 52.1 & 49.0 & 39.8 & 55.4 & 56.8 \\
\hline 2011 & 51.1 & 50.8 & 36.1 & 56.9 & 33.9 & 52.7 & 49.6 & 43.0 & 55.3 & 56.8 \\
\hline 2012 & 54.8 & 54.2 & 42.5 & 59.9 & 39.7 & 57.3 & 52.2 & 46.3 & 56.2 & 60.6 \\
\hline 2013 & 52.2 & 51.9 & 35.3 & 58.0 & 37.1 & 54.7 & 49.7 & 42.8 & 52.7 & 59.1 \\
\hline 2014 & 51.3 & 51.6 & 33.7 & 56.3 & 40.9 & 52.9 & 49.8 & 41.1 & 54.0 & 58.8 \\
\hline 2015 & 50.5 & 50.7 & 32.3 & 55.0 & 42.1 & 51.8 & 49.2 & 41.0 & 52.1 & 58.7 \\
\hline 2016 & 49.9 & 50.3 & 32.8 & 54.8 & 40.1 & 51.4 & 48.3 & 41.0 & 50.0 & 59.6 \\
\hline 2017 & 52.9 & 53.3 & 35.5 & 57.5 & 44.3 & 56.1 & 49.8 & 44.0 & 54.7 & 59.5 \\
\hline 2018 & 52.4 & 52.8 & 37.1 & 56.9 & 43.1 & 55.7 & 49.1 & 42.5 & 52.8 & 61.3 \\
\hline
\end{tabular}

* Based on population size of $\geq 12$ years old. ${ }^{\dagger}$ Based on population size of $\geq 25$ years old and categorized by highest attained level of education. ${ }^{\delta}$ low (no, elementary, or low vocational/secondary schooling), intermediate (intermediate vocational or intermediate/higher secondary schooling), or high (higher vocational schooling or university). 
Table A4. Adherence levels to the second component of the Dutch physical activity guidelines consisting of two times per week bone and muscle strengthening activities for adults, three times for adolescents, stratified by age groups, sex, and level of education.

\begin{tabular}{|c|c|c|c|c|c|c|c|c|c|c|}
\hline \multirow[b]{2}{*}{ Year } & \multicolumn{2}{|c|}{ Total (\%) } & \multicolumn{3}{|c|}{ Age Group (\%)* } & \multicolumn{2}{|c|}{$\operatorname{Sex}(\%) *$} & \multicolumn{3}{|c|}{ Level of Education $(\%){ }^{\dagger, \delta}$} \\
\hline & $\begin{array}{l}\geq 12 \\
\text { Years }\end{array}$ & $\begin{array}{l}\geq 25 \\
\text { Years }\end{array}$ & $\begin{array}{c}\text { Adolescents } \\
(12-17)\end{array}$ & $\begin{array}{l}\text { Adults } \\
(18-64)\end{array}$ & $\begin{array}{c}\text { Seniors } \\
(65+)\end{array}$ & Male & Female & Lower & Intermediate & Higher \\
\hline 2001 & 71.8 & 70.2 & 82.5 & 73.3 & 58.8 & 70.3 & 73.3 & 62.2 & 71.9 & 81.5 \\
\hline 2002 & 72.3 & 70.7 & 82.6 & 73.6 & 61.1 & 70.3 & 74.2 & 62.8 & 72.0 & 81.5 \\
\hline 2003 & 72.8 & 71.3 & 81.5 & 73.9 & 62.3 & 72.5 & 73.2 & 63.3 & 72.8 & 81.9 \\
\hline 2004 & 73.2 & 71.7 & 83.8 & 74.9 & 59.4 & 71.8 & 74.6 & 60.7 & 73.0 & 80.5 \\
\hline 2005 & 74.2 & 72.8 & 82.8 & 76.1 & 61.4 & 72.3 & 76.1 & 65.2 & 74.5 & 83.0 \\
\hline 2006 & 73.8 & 71.8 & 85.0 & 75.1 & 62.1 & 72.9 & 74.6 & 62.5 & 74.1 & 83.2 \\
\hline 2007 & 74.7 & 73.2 & 83.7 & 77.0 & 61.0 & 73.2 & 76.2 & 65.2 & 76.3 & 81.2 \\
\hline 2008 & 74.8 & 73.5 & 84.2 & 76.8 & 62.8 & 73.2 & 76.3 & 64.5 & 74.8 & 83.8 \\
\hline 2009 & 73.2 & 71.1 & 81.4 & 75.5 & 61.0 & 71.5 & 74.8 & 63.4 & 69.9 & 81.3 \\
\hline 2010 & 74.6 & 73.6 & 79.1 & 77.4 & 60.1 & 72.4 & 76.7 & 63.5 & 76.3 & 84.5 \\
\hline 2011 & 74.8 & 73.1 & 84.2 & 76.5 & 63.4 & 71.9 & 77.6 & 64.3 & 75.0 & 83.2 \\
\hline 2012 & 75.2 & 74.1 & 80.0 & 77.2 & 65.3 & 74.0 & 76.5 & 64.2 & 75.3 & 83.6 \\
\hline 2013 & 75.9 & 75.0 & 79.1 & 78.1 & 66.0 & 74.0 & 77.8 & 63.3 & 76.4 & 84.0 \\
\hline 2014 & 74.5 & 73.7 & 79.8 & 76.3 & 65.4 & 72.3 & 76.6 & 62.8 & 74.4 & 83.4 \\
\hline 2015 & 75.2 & 74.4 & 79.1 & 76.9 & 67.6 & 73.5 & 76.8 & 63.6 & 74.9 & 84.5 \\
\hline 2016 & 75.2 & 74.7 & 81.0 & 76.6 & 68.1 & 73.6 & 76.9 & 64.6 & 73.7 & 85.8 \\
\hline 2017 & 76.5 & 76.2 & 78.9 & 78.3 & 69.5 & 74.5 & 78.5 & 67.9 & 74.7 & 85.0 \\
\hline 2018 & 78.2 & 77.6 & 84.2 & 79.1 & 72.9 & 78.2 & 78.3 & 67.4 & 77.3 & 86.3 \\
\hline
\end{tabular}

${ }^{*}$ Based on population size of $\geq 12$ years old. ${ }^{+}$Based on population size of $\geq 25$ years old and categorized by highest attained level of education. ${ }^{\delta}$ low (no, elementary, or low vocational/secondary schooling), intermediate (intermediate vocational or intermediate/higher secondary schooling), or high (higher vocational schooling or university).

\section{References}

1. Forouzanfar, M.H.; Afshin, A.; Alexander, L.T.; Anderson, H.R.; Bhutta, Z.A.; Biryukov, S.; Brauer, M.; Burnett, R.; Cercy, K.; Charlson, F.J.; et al. Global, regional, and national comparative risk assessment of 79 behavioural, environmental and occupational, and metabolic risks or clusters of risks, 1990-2015: A systematic analysis for the Global Burden of Disease Study 2015. Lancet 2016, 388, 1659-1724. [CrossRef]

2. Guthold, R.; Stevens, G.A.; Riley, L.M.; Bull, F.C. Worldwide trends in insufficient physical activity from 2001 to 2016: A pooled analysis of 358 population-based surveys with 1.9 million participants. Lancet Glob. Health 2018, 6, e1077-e1086. [CrossRef]

3. Lee, I.-M.; Shiroma, E.J.; Lobelo, F.; Puska, P.; Blair, S.N.; Katzmarzyk, P.T. Lancet Physical Activity Series Working Group. Effect of physical inactivity on major non-communicable diseases worldwide: An analysis of burden of disease and life expectancy. Lancet 2012, 380, 219-229. [CrossRef]

4. Ding, D.; Lawson, K.D.; Kolbe-Alexander, T.L.; Finkelstein, E.A.; Katzmarzyk, P.T.; Van Mechelen, W.; Pratt, M. Lancet Physical Activity Series 2 Executive Committee The economic burden of physical inactivity: A global analysis of major non-communicable diseases. Lancet 2016, 388, 1311-1324. [CrossRef]

5. World Health Organization. Global Action Plan for the Prevention and Control of Noncommunicable Diseases 2013-2020; World Health Organization: Geneva, Switzerland, 2013.

6. World Health Organization. Global Action Plan on Physical Activity 2018-2030: More Active People for a Healthier World; World Health Organization: Geneva, Switzerland, 2018.

7. Ministry of Health Welfare and Sport. Nationaal Sportakkoord Sport Verenigt Nederland; Ministry of Health Welfare and Sport: The Hague, The Netherlands, 2018.

8. Ministry of Infrastructure and Water Management. Agenda Fiets 2017-2020; Ministry of Infrastructure and Water Management: The Hague, The Netherlands, 2017.

9. Ministry of Health Welfare and Sport. Nationaal Preventieakkoord; Ministry of Health Welfare and Sport: The Hague, The Netherlands, 2018.

10. Weggemans, R.M.; Backx, F.J.G.; Borghouts, L.; Chinapaw, M.; Hopman, M.T.E.; Koster, A.; Kremers, S.; Van Loon, L.J.C.; May, A.; Mosterd, A.; et al. The 2017 Dutch Physical Activity Guidelines. Int. J. Behav. Nutr. Phys. Act. 2018, 15, 58. [CrossRef] [PubMed] 
11. The Health Council of the Netherlands. Advies Beweegrichtlijnen 2017. Available online: https://www. gezondheidsraad.nl/documenten/adviezen/2017/08/22/beweegrichtlijnen-2017 (accessed on 7 January 2019).

12. Kemper, H.; Ooijendijk, W.; Stiggelbout, M. Consensus Over de Nederlandse Norm Voor Gezond Bewegen; TNO: Den Haag, The Netherlands, 2000.

13. Ding, D.; Varela, A.R.; Bauman, A.E.; Ekelund, U.; Lee, I.-M.; Heath, G.; Katzmarzyk, P.T.; Reis, R.; Pratt, M. Towards better evidence-informed global action: Lessons learnt from the Lancet series and recent developments in physical activity and public health. Br. J. Sports Med. 2019. [CrossRef] [PubMed]

14. Kohl, H.W., 3rd; Craig, C.L.; Lambert, E.V.; Inoue, S.; Alkandari, J.R.; Leetongin, G.; Kahlmeier, S.; Lancet Physical Activity Series Working Group. The pandemic of physical inactivity: Global action for public health. Lancet 2012, 380, 294-305. [CrossRef]

15. Breda, J.; Jakovljevic, J.; Rathmes, G.; Mendes, R.; Fontaine, O.; Hollmann, S.; Rütten, A.; Gelius, P.; Kahlmeier, S.; Galea, G. Promoting health-enhancing physical activity in Europe: Current state of surveillance, policy development and implementation. Health Policy 2018, 122, 519-527. [CrossRef] [PubMed]

16. Bennie, J.A.; Pedisic, Z.; Van Uffelen, J.G.Z.; Gale, J.; Banting, L.K.; Vergeer, I.; Stamatakis, E.; Bauman, A.E.; Biddle, S.J.H. The descriptive epidemiology of total physical activity, muscle-strengthening exercises and sedentary behaviour among Australian adults-results from the National Nutrition and Physical Activity Survey. BMC Public Health 2016, 16, 73. [CrossRef] [PubMed]

17. Vuori, I.; Lankenau, B.; Pratt, M. Physical activity policy and program development: The experience in Finland. Public Health Rep. 2004, 119, 331-345. [CrossRef] [PubMed]

18. Stamatakis, E.; Ekelund, U.; Wareham, N.J. Temporal trends in physical activity in England: The Health Survey for England 1991 to 2004. Prev. Med. 2007, 45, 416-423. [CrossRef] [PubMed]

19. Du, Y.; Liu, B.; Sun, Y.; Snetselaar, L.G.; Wallace, R.B.; Bao, W. Trends in adherence to the physical activity guidelines for Americans for aerobic activity and time spent on sedentary behavior among US adults, 2007 to 2016. JAMA Netw. 2019, 2, e197597. [CrossRef] [PubMed]

20. Carlson, S.A.; Fulton, J.E.; Schoenborn, C.A.; Loustalot, F. Trend and Prevalence Estimates Based on the 2008 Physical Activity Guidelines for Americans. Am. J. Prev. Med. 2010, 39, 305-313. [CrossRef] [PubMed]

21. Bennie, J.A.; De Cocker, K.; Teychenne, M.J.; Brown, W.J.; Biddle, S.J.H. The epidemiology of aerobic physical activity and muscle-strengthening activity guideline adherence among 383,928 U.S. adults. Int. J. Behav. Nutr. Phys. Act. 2019, 16, 34. [CrossRef] [PubMed]

22. Sjöström, M.; Oja, P.; Hagströmer, M.; Smith, B.J.; Bauman, A. Health-enhancing physical activity across European Union countries: The Eurobarometer study. J. Public Health 2006, 14, 291-300. [CrossRef]

23. Hallal, P.C.; Andersen, L.B.; Bull, F.C.; Guthold, R.; Haskell, W.; Ekelund, U. Global physical activity levels: Surveillance progress, pitfalls, and prospects. Lancet 2012, 380, 247-257. [CrossRef]

24. Bauman, A.; Ford, I.; Armstrong, T. Trends in Population Levels of Reported Physical Activity in Australia, 1997, 1999 and 2000; Australian Sports Commission: Canberra, Australia, 2001.

25. Strain, T.; Fitzsimons, C.; Kelly, P.; Mutrie, N. The forgotten guidelines: Cross-sectional analysis of participation in muscle strengthening and balance \& co-ordination activities by adults and older adults in Scotland. BMC Public Health 2016, 16, 1108.

26. Milton, K.; Varela, A.R.; Strain, T.; Cavill, N.; Foster, C.; Mutrie, N. A review of global surveillance on the muscle strengthening and balance elements of physical activity recommendations. J. Frailty Sarcopenia Falls 2018, 3, 114-124. [CrossRef]

27. Statistics Netherlands. Gezondheidsenquête 1981-1996 en POLS-Gezondheid 1997-2009. Available online: https:/www.cbs.nl/nl-nl/onze-diensten/methoden/onderzoeksomschrijvingen/ korte-onderzoeksbeschrijvingen/gezondheidsenquete-1981-1996-en-pols-gezondheid-1997-2009 (accessed on 6 December 2019).

28. Statistics Netherlands. Vragenlijsten Gezondheidsenquête 2010 t/m 2013; Statistics Netherlands: Den Haag, The Netherlands, 2013.

29. Statistics Netherlands. Gezondheidsenquête Vanaf 2014. Available online: https://www.cbs.nl/nl-nl/onzediensten/methoden/onderzoeksomschrijvingen/korte-onderzoeksbeschrijvingen/gezondheidsenquetevanaf-2014 (accessed on 6 December 2019).

30. Statistics Netherlands, National Institute for Public Health and the Environment. Health Survey/Lifestyle Monitor; Statistics Netherlands (CBS) in collaboration with National Institute for Public Health and the Environment (RIVM): The Hague/Bilthoven, The Netherlands, 2001-2018. 
31. Statistics Netherlands. Permanent Onderzoek Leefsituatie: Basis. Available online: https://www.scp.nl/Onderzoek/Bronnen/Beknopte_onderzoeksbeschrijvingen/Permanent_onderzoek_ naar_de_leefsituatie_POLS (accessed on 6 December 2019).

32. Boonstra, H.J. Weging Gezondheidsenquete 2014; Statistics Netherlands: Den Haag, The Netherlands, 2015.

33. Wendel-Vos, G. Reproducibility and relative validity of the short questionnaire to assess health-enhancing physical activity. J. Clin. Epidemiol. 2003, 56, 1163-1169. [CrossRef]

34. Campbell, N.; Gaston, A.; Gray, C.; Rush, E.; Maddison, R.; Prapavessis, H. The Short Questionnaire to Assess Health-Enhancing (SQUASH) Physical Activity in Adolescents: A Validation Using Doubly Labeled Water. J. Phys. Act. Health 2016, 13, 154-158. [CrossRef]

35. Makabe, S.; Makimoto, K.; Kikkawa, T.; Uozumi, H.; Ohnuma, M.; Kawamata, T. Reliability and validity of the Japanese version of the short questionnaire to assess health-enhancing physical activity (SQUASH squash) scale in older adults. J. Phys. Ther. Sci. 2015, 27, 517-522. [CrossRef] [PubMed]

36. Wagenmakers, R.; Akker-Scheek, I.V.D.; Groothoff, J.W.; Zijlstra, W.; Bulstra, S.K.; Kootstra, J.W.; Wendel-Vos, G.W.; Van Raaij, J.J.; Stevens, M. Reliability and validity of the short questionnaire to assess health-enhancing physical activity (SQUASH) in patients after total hip arthroplasty. BMC Musculoskelet. Disord. 2008, 9, 141. [CrossRef] [PubMed]

37. Ainsworth, B.E.; Haskell, W.L.; Whitt, M.C.; Irwin, M.L.; Swartz, A.M.; Strath, S.J.; O'brien, W.L.; Bassett, D.R.; Schmitz, K.H.; Emplaincourt, P.O.; et al. Compendium of physical activities: An update of activity codes and MET intensities. Med. Sci. Sports Exerc. 2000, 32, S498-S516. [CrossRef]

38. Kumar, A.; Saxena, M.; Hammond, N.; Taylor, C.; Thompson, K.; Grattan, S. Near Two-fold Rise in ICD-coded Sepsis-related Hospital Admissions in Australia: An Australian Institute of Health and Welfare Database Analysis (2011-2016). Aust. Crit. Care 2019, 32, S7. [CrossRef]

39. Scholes, S. Health Survey for England 2016 Physical Activity in Adults 978-1-78734-099-2; HSCIC: Leeds, UK, 2017.

40. Loyen, A.; Van Hecke, L.; Verloigne, M.; Hendriksen, I.; Lakerveld, J.; Steene-Johannessen, J.; Vuillemin, A.; Koster, A.; Donnelly, A.; Ekelund, U.; et al. Variation in population levels of physical activity in European adults according to cross-European studies: A systematic literature review within DEDIPAC. Int. J. Behav. Nutr. Phys. Act. 2016, 13, 72. [CrossRef] [PubMed]

41. Morren, M.; Willems, R. Gezondheidsenquête 2014: Een Analyse Van de Methodebreuk; Statistics Netherlands: Heerlen, The Netherlands, 2015.

42. Troiano, R.P. A timely meeting: Objective measurement of physical activity. Med. Sci. Sports Exerc. 2005, 37, S487-S489. [CrossRef]

43. Loyen, A.; Clarke-Cornwell, A.M.; Anderssen, S.A.; Hagströmer, M.; Sardinha, L.B.; Sundquist, K.; Ekelund, U.; Steene-Johannessen, J.; Baptista, F.; Hansen, B.H.; et al. Sedentary Time and Physical Activity Surveillance Through Accelerometer Pooling in Four European Countries. Sports Med. 2017, 47, 1421-1435. [CrossRef]

44. Holtermann, A.; Hansen, J.; Burr, H.; Søgaard, K.; Sjøgaard, G. The health paradox of occupational and leisure-time physical activity. Br. J. Sports Med. 2012, 46, 291-295. [CrossRef]

45. Althoff, T.; Sosič, R.; Hicks, J.L.; King, A.C.; Delp, S.L.; Leskovec, J. Large-scale physical activity data reveal worldwide activity inequality. Nature 2017, 547, 336-339. [CrossRef]

46. King, A.C.; King, D.K. Physical Activity for an Aging Population. Public Health Rev. 2010, 32, 401-426. [CrossRef]

47. Telama, R. Tracking of physical activity from childhood to adulthood: A review. Obes. Facts 2009, 2, 187-195. [CrossRef] [PubMed]

48. Rovio, S.P.; Yang, X.; Kankaanpää, A.; Aalto, V.; Hirvensalo, M.; Telama, R.; Pahkala, K.; Hutri-Kähönen, N.; Viikari, J.S.; Raitakari, O.T. Longitudinal physical activity trajectories from childhood to adulthood and their determinants: The Young Finns Study. Scand. J. Med. Sci. Sports 2018, 28, 1073-1083. [CrossRef]

49. Drieskens, S.; Van Oyen, H.; Demarest, S.; Van der Heyden, J.; Gisle, L.; Tafforeau, J. Multiple risk behaviour: Increasing socio-economic gap over time? Eur. J. Public Health 2010, 20, 634-639. [CrossRef]

50. Smith, P.; Frank, J.; Mustard, C. Trends in educational inequalities in smoking and physical activity in Canada: 1974-2005. J. Epidemiol. Community Health 2009, 63, 317-323. [CrossRef] [PubMed] 
51. Ding, D.; Do, A.; Schmidt, H.-M.; Bauman, A.E. A widening gap? Changes in multiple lifestyle risk behaviours by socioeconomic status in New South Wales, Australia, 2002-2012. PLoS ONE 2015, 10, e0135338. [CrossRef]

52. Elgar, F.J.; Pförtner, T.-K.; Moor, I.; De Clercq, B.; Stevens, G.W.J.M.; Currie, C. Socioeconomic inequalities in adolescent health 2002-2010: A time-series analysis of 34 countries participating in the Health Behaviour in School-aged Children study. Lancet 2015, 385, 2088-2095. [CrossRef]

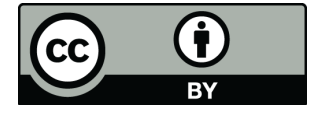

(C) 2020 by the authors. Licensee MDPI, Basel, Switzerland. This article is an open access article distributed under the terms and conditions of the Creative Commons Attribution (CC BY) license (http://creativecommons.org/licenses/by/4.0/). 